\title{
NOTES
}

\section{Effect of Reaction Temperature on Polyurethane Formation in Bulk}

\author{
Takao ANDo \\ SANYO Chemical Industries, Ltd., Research Division \\ 11-1, Ikkyo Nomoto-cho, Higashiyama-ku, Kyoto 605, Japan
}

(Received June 14, 1993)

\begin{abstract}
KEY WORDS Bulk Polyurethane Formation / Reaction Temperature / Molecular Weight / Kinetic Parameters / DSC /
\end{abstract}

Polyurethanes prepared in bulk are widely used as coatings, adhesives and elastomers because of their excellent properties. Although the polyurethane formation in solution has been studied extensively, ${ }^{1,2}$ few studies have been reported on kinetics of the polyurethane formation in bulk. ${ }^{3-8}$ No study has been also reported on the reaction temperature which gives the polyurethane with various molecular weights for the shortest reaction time in bulk, although his kind of study is industrially important. In this paper, to this end the reaction of $4,4^{\prime}$-diisocyanatodiphenylmethane (MDI) with a mixture of poly(ethyleneadipate) diol (PEA, $M_{n}=2000$ ) and ethylene glycol (EG) (molar ratio $=1: 2$ ) was studied to clarify the effects of reaction temperature of the polyurethane formation in bulk on molecular weight $\left(M_{n}\right)$ of the resulting polyurethane. The $M_{n}$ of the polyurethane, when the rate of urethane formation is the same as that of

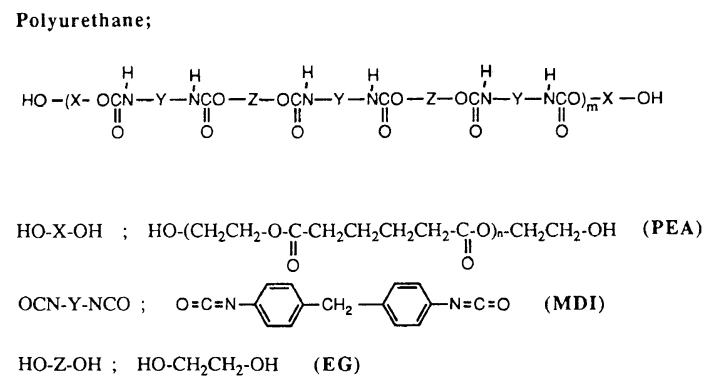

urethane dissociation, was calculated from the kinetic parameters of polyurethane formation and dissociation obtained by differential scanning calorimetry (DSC).

\section{EXPERIMENTAL}

\section{Materials}

4,4'-Diisocyanatodiphenylmethane (MDI, Nippon Polyurethane Industry Co., Ltd.), poly(ethyleneadipate) diol having two terminal hydroxyl groups (PEA, $M_{n}=2000$, Sanyo Chemical Industries, Ltd.) and ethylene glycol (EG, Mitsubishi Petrochemical Co., Ltd.) were used as received without further purification.

\section{Polyurethane Formation}

Polyurethane was prepared in bulk by the reaction of MDI with a mixture of PEA and EG (molar ratio $=1: 2 ; \mathrm{NCO} / \mathrm{OH}$ molar ratio $=1.00)$ at constant temperature using a twin-screw extruder (Kurimoto, Ltd., $20 \mathrm{~mm}$ diameter, $L / D=10$ ).

\section{Measurement of the Molecular Weight of Polyurethane}

The molecular weight of the polyurethane was determined by gel permeation chromatography (GPC) in $N, N$-dimethylformamide (DMF) after quenching the reaction by the addition of a large excess of $n$-propyl alcohol. 
Polystyrene standards were used for calculation of the molecular weight.

Measurement of the Kinetic Parameters of Polyurethane Formation and Dissociation

The mixture of MDI and the above diol in a pan of DSC was subjected to a controlled temperature ramp $10-120^{\circ} \mathrm{C}, 10^{\circ} \mathrm{C} \mathrm{min}^{-1}$ under an atmosphere of argon, and the kinetics of urethane formation was determined by DSC (Perkin-Elmer Series 7000). The activation energy $\left(E_{\mathrm{a}}\right)$ and frequency factor $(A)$ of urethane formation were calculated by the DSC7 Kinetics Software (Perkin-Elmer). Similarly the polyurethane in a pan of DSC was subjected to a controlled temperature ramp $140-240^{\circ} \mathrm{C}, 10^{\circ} \mathrm{C} \mathrm{min}^{-1}$ under an atmosphere of argon, and the kinetic parameters of urethane dissociation were determined by the same method.

\section{RESULTS AND DISCUSSION}

Polyurethane was prepared in bulk by the reaction of MDI with a mixture of PEA and $\mathrm{EG}$ (molar ratio $=1: 2 ; \mathrm{NCO} / \mathrm{OH}$ molar ratio $=1.00)$ at constant temperature.

Figure 1 shows the effects of reaction temperature of polyurethane formation in bulk

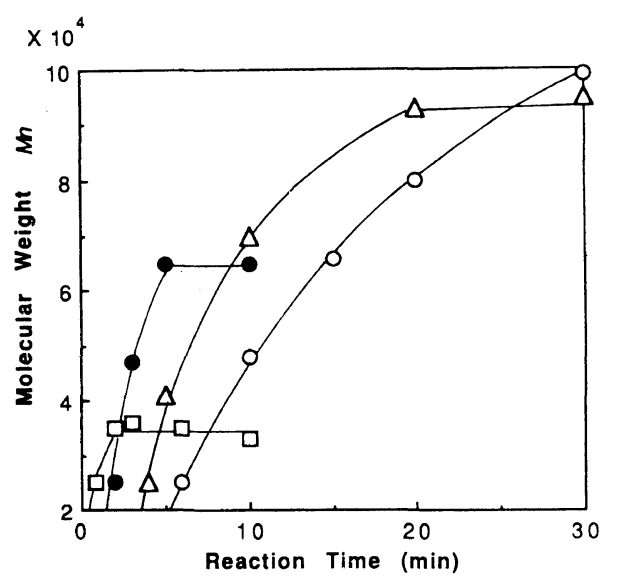

Figure 1. Polyurethane formation in bulk. Relations between reaction time and $M_{n}$ at different reaction temperature; $\mathrm{O}: 180^{\circ} \mathrm{C}, \triangle: 200^{\circ} \mathrm{C} \bigcirc: 220^{\circ} \mathrm{C}, \square: 240^{\circ} \mathrm{C}$. on the molecular weight $\left(M_{n}\right)$ of the resulting polyurethane.

These results indicate that the rate of molecular weight increase was higher and the maximum molecular weight of the resulting polyurethane was lower at higher reaction temperatures. The polyurethane with high molecular weight could not be obtained at higher reaction temperatures although higher reaction temperature is preferable to accelerate the formation of polyurethane. It was found for the first time that the maximum molecular weight of the polyurethane prepared in bulk could be controlled by the reaction temperature. Furthermore, the reaction temperature which gives the polyurethane with various molecular weights for the shortest reaction time was found.

Then the reasons for the results shown in Figure 1 are discussed. It is thought that increase in the dissociation of urethane linkages compared to the formation of them caused by the higher reaction temperature results in decrease in the maximum molecular weight reached. This hypothesis is discussed from the standpoint of the kinetics. The kinetic expression shown below was chosen to describe the reaction rates of the urethane formation and dissociation.

$$
\begin{aligned}
\mathrm{d}[\mathrm{U}] / \mathrm{d} t & =k_{\mathrm{f}}[\mathrm{NCO}][\mathrm{OH}] \\
-\mathrm{d}[\mathrm{U}] / \mathrm{d} t & =k_{\mathrm{d}}[\mathrm{U}]
\end{aligned}
$$

where $[\mathrm{U}],[\mathrm{NCO}]$, and $[\mathrm{OH}]$ are the concentrations of urethane linkages, isocyanate group and hydroxyl group, respectively.

When the polyurethane is

$$
\text { MDI-(DIOL - MDI) })_{n} \text { DIOL }
$$

where $M_{n}$ of DIOL is 700 and $M_{n}$ of MDI is 250 , hence,

$$
\begin{aligned}
& {[\mathrm{U}]=(2 n+1) / 950(n+1)} \\
& {[\mathrm{NCO}]=[\mathrm{OH}]=1 / 950(n+1)}
\end{aligned}
$$

and $M_{n}$ of the polyurethane is $950(n+1)$.

An Arrhenius temperature dependence is 
Table I. The kinetic parameters of urethane formation and dissociation determined by $\mathrm{DSC}^{\mathrm{a}}$

\begin{tabular}{|c|c|c|c|}
\hline & \multicolumn{2}{|c|}{$A$} & \multirow{2}{*}{$\frac{E_{\mathrm{a}}}{\mathrm{cal} \mathrm{mol}^{-1}}$} \\
\hline & $\mathrm{kg} \mathrm{mol}^{-1} \mathrm{~s}^{-1}$ & $\mathrm{~s}^{-1}$ & \\
\hline $\begin{array}{l}\text { Urethane } \\
\text { formation }\end{array}$ & $8.52 \times 10^{7}$ & - & $1.51 \times 10^{4}$ \\
\hline $\begin{array}{l}\text { Urethane } \\
\text { dissociation }\end{array}$ & - & $3.05 \times 10^{14}$ & $4.53 \times 10^{4}$ \\
\hline
\end{tabular}

a Kinetic parameters determined by the DSC7 Kinetics Software (Perkin-Elmer).

Table II. The calculated $M_{n}$ of the polyurethane when the rate of urethane formation is the same as that of urethane dissociation, and saturated $M_{n}$ observed at different reaction temperature

\begin{tabular}{ccc}
\hline Temperature $/{ }^{\circ} \mathrm{C}$ & Calculated $M_{n}$ & $\begin{array}{c}\text { Saturated } M_{n} \\
\text { Observed }^{\text {a }}\end{array}$ \\
\hline 180 & $22.5 \times 10^{4}$ & - \\
200 & $11.1 \times 10^{4}$ & $9.2 \times 10^{4}$ \\
220 & $5.7 \times 10^{4}$ & $6.5 \times 10^{4}$ \\
240 & $3.2 \times 10^{4}$ & $3.5 \times 10^{4}$
\end{tabular}

a Observed $M_{n}$ determined by GPC, polystyrene standards.

assumed as

$$
k=A e^{-\mathrm{E}_{\mathrm{a}} \mathrm{RT}}
$$

$E_{\mathrm{a}}$, activation energy; $A$, frequency factor

The kinetic parameters of the urethane for- mation and dissociation are summarized in Table I. The molecular weight $\left(M_{n}\right)$ of the polyurethane, when the rate of urethane formation is the same as that of urethane dissociation at constant temperature was calculated from the parameters shown in Table I. These calculated values and maximum $M_{n}$ observed at various reaction temperatures shown in Figure 1 are summarized in Table II.

These calculated values are in fair agreement with the observed values, suggesting that increase in the dissociation of urethane linkages compared to the formation of them caused by the higher reaction temperature results in decrease in the maximum molecular weight.

\section{REFERENCES}

1. J. H. Saunders and K. C. Frisch,"Polyurethanes Part I, Chemistry," Interscience, New York, 1962, pp 134-161.

2. G. Borkent and J. J. Van Ardsten, "Advances in Urethane Science and Technology," Vol. 3, Technomic Publishers, Conn., 1974, pp 1-10.

3. E. B. Gyevi and F. Tudes, Acta. Chim., 81, 191 (1974).

4. S. D. Lipshitz, F. G. Musatti, and C. W. Macosko, SPE ANTEC Tech. Paper, 21, 239 (1975).

5. S. D. Lipshitz and C. W. Macosko, Polym. Eng. Sci., 16, 803 (1976)

6. S. D. Lipshitz and C. W. Macosko, J. Appl. Polym. Sci., 21, 2029 (1977).

7. E. Broyer, C. W. Macosko, F. C. Critchfield, and L. F. Lawler, Polym. Eng. Sci., 18, 382 (1978).

8. E. B. Richter and C. W. Macosko, Polym. Eng. Sci., 18, 1012 (1978). 